\title{
Explaining the SPoARC and SNARC effects with knowledge structures: An expertise account
}

\author{
Alessandro Guida ${ }^{1} \cdot$ Guillermo Campitelli ${ }^{2}$
}

Published online: 18 March 2019

(C) The Psychonomic Society, Inc. 2019

\begin{abstract}
Two proposals have been put forward to account conjointly for the spatial-numerical association of response codes (SNARC) effect and the spatial-positional association of response codes (SPoARC) effect: the working memory account and the dual account. Here, on the basis of experimental and theoretical knowledge acquired in the field of expert memory, we propose an alternative accountnamed the expertise account - that explains both effects through the acquisition and use of knowledge structures (a generalization of "chunks," "retrieval structures," and "templates"), which have been used extensively in expert memory theory. These knowledge structures can be of two types: nonslotted or slotted schemas. We suggest that the SNARC effect can be explained via the use of nonslotted schemas, and the SPoARC effect via slotted schemas. We conclude our article by presenting the broader implications of our framework for working memory in general, when considering knowledge structures.
\end{abstract}

Keywords SPoARC - SNARC - Verbal working memory - Ordinal position effect - Retrieval structures · Templates · Mathematical cognition $\cdot$ Spatial cognition $\cdot$ Expertise $\cdot$ Working memory

The goal of this article is to provide an expertise account of two spatial effects: the spatial-numerical association of response codes (SNARC) effect observed in numerical cognition (Dehaene, Bossini, \& Giraux, 1993), and the spatialpositional association of response codes (SPoARC) effect observed in memory research (van Dijck \& Fias, 2011). This expertise account builds upon experimental and theoretical knowledge acquired in the field of expert memory (e.g., Campitelli, 2015; Ericsson \& Kintsch, 1995; Gobet \& Simon, 1996; Guida, Gobet, Tardieu, \& Nicolas, 2012). More specifically, we will employ the concept of "knowledge structures," a generalization of the concepts of "chunks," "retrieval structures," and "templates," which have been extensively used to explain results in memory experts (Chase \& Simon, 1973; Ericsson \& Kintsch, 1995; Gobet \& Simon, 1996; Gobet, Lane, \& Lloyd-Kelly, 2015; Williamon \& Valentine, 2002).

Alessandro Guida alessandro.guida@univ-rennes2.fr; alessandro.guida.psychology@gmail.com

LP3C, Université Rennes, Rennes, France

2 Murdoch University, Perth, Australia
The article is organized in three main sections: First, we present the SNARC and SPoARC effects; second, we describe the three main theories of expertise; and third, we provide our expertise account of the SNARC and SPoARC effects, indicating how the expertise account contrasts with the previous accounts.

\section{The SNARC and SPoARC effects}

SNARC and SPoARC are effects in which the items in memory seem to be organized along a vertical or horizontal dimension following a particular direction. We will refer to this general phenomenon as spatialization (Guida, Carnet, Normandon, \& Lavielle-Guida, 2018), in which the cognitive system adds a spatial organization to presented information. Figure 1 illustrates the paradigms used to test SNARC, SPoARC, or both effects together.

\section{The SNARC effect and similar spatializations}

In their seminal article, Dehaene et al. (1993) investigated the SNARC effect in nine experiments using odd-even judgments. As is shown in the first row of Fig. 1, participants had to press a key to indicate whether a number presented in the middle of the screen was odd or even. In half of the trials 


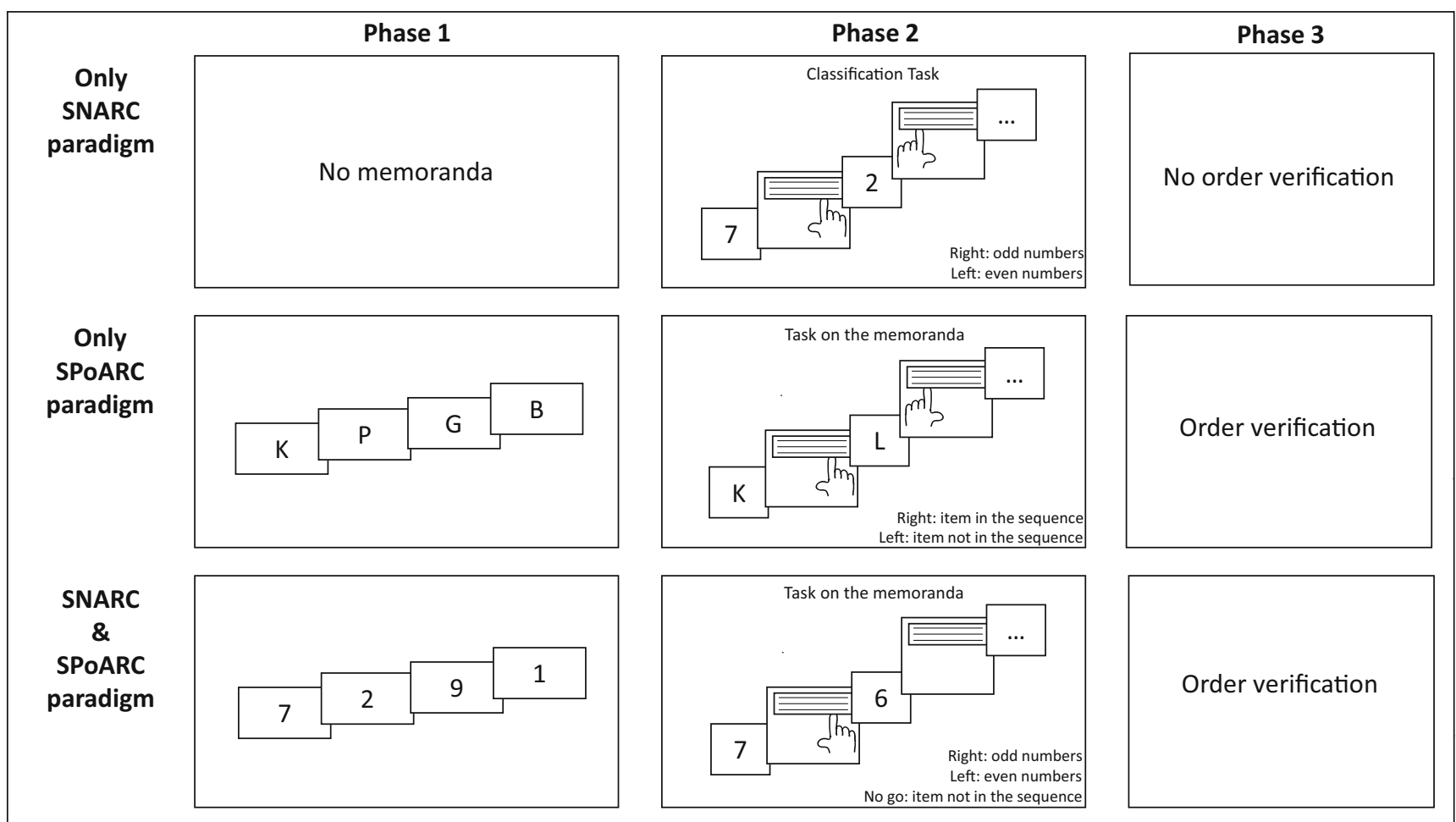

Fig. 1 Designs for testing only the SNARC effect, only the SPOARC effect, or both effects. Phase 2 in the figure presents one type of association between the stimuli and the responses (e.g., right: odd numbers), which usually represents $50 \%$ of the trials; the converse association is not presented (e.g., left: odd numbers) but is executed by the participants (remaining $50 \%$ of trials) they had to use one hand for odd numbers and the other hand for even numbers and in the other half the hand assignment was reversed. The authors found that small numbers (e.g., 1, 2 ) were responded faster with the left hand and large numbers (e.g., 8, 9) were responded faster with the right hand.

The SNARC effect was found to be robust, no matter if the participants were left-handed or if they crossed hands (Dehaene et al., 1993; but see Wood, Nuerk, \& Willmes, 2006), and it was observed with different tasks and formats, such as number comparison tasks (participants had to indicate whether a displayed number was bigger or smaller than a reference number; e.g., Brysbaert, 1995; Dehaene, Dupoux, \& Mehler, 1990), one- or two-digit numbers (e.g., Brysbaert, 1995; Dehaene et al., 1993; Dehaene et al., 1990), or even with words (Dehaene et al., 1993; Fias, 2001), instead of Arabic digits, to represent numbers (for reviews of the SNARC effect, see Abrahamse, van Dijck, \& Fias, 2016; Fias \& Fischer, 2005; Fias, van Dijck, \& Gevers, 2011; Gevers \& Lammertyn, 2005; Wood, Willmes, Nuerk, \& Fischer, 2008). Interestingly, the SNARC effect was reversed in studies with participants from right-to-left reading cultures (e.g., Dehaene et al., 1993; Shaki, Fischer, \& Petrusic, 2009; Zebian, 2005), and shifted to a vertical orientation in Chinese (Hung, Hung, Tzeng, \& Wu, 2008) or Japanese (Ito \& Hatta, 2004) participants, who read top-down.
The SNARC effect is not limited to numbers: It has been found with days of the week (Gevers, Reynvoet, \& Fias, 2004), months of the year, and letters (Gevers, Reynvoet, \& Fias, 2003). In all these experiments, participants were shown a stimulus (e.g., "Monday," "April," or "B") and had to indicate using both hands whether the stimulus came before or after a reference stimulus (e.g., "Wednesday," "July," or "R," respectively), or whether or not the stimulus contained a specific feature (e.g., "a vowel"). In all these experiments, the left hand tended to be faster for stimuli at the beginning of the ordinal sequences, whereas the right hand tended to be faster with the last part of the ordinal sequences. More recently, Sellaro, Treccani, Job, and Cubelli (2015) showed a SNARC-like effect for the size of objects, with left responses being faster for small objects and right responses, for large objects.

Interestingly, the SNARC effect can be made disappear if working memory (WM) load is added to a task. Herrera, Macizo, and Semenza (2008) showed that when a number comparison task is administrated during the retention interval of a spatial WM task, SNARC disappears; contrarily, it does not disappear when the number comparison task is embedded within a verbal WM task. Van Dijck, Gevers, and Fias (2009) observed the reverse pattern when the number comparison is replaced by an odd-even judgment task. Overall these results show that numbers are associated with different spatial codes, 
which can have a visuospatial (i.e., number comparison) or verbally (i.e., odd-even judgment) mediated nature depending on the task.

\section{The SPoARC effect}

The SPoARC effect-also known as the ordinal position effect (Ginsburg, van Dijck, Previtali, Fias, \& Gevers, 2014; not to be mistaken with Becker's, 1953, ordinal position effect, which refers to the effect of speaking order on the perceived quality of a speech) - was first brought to light by van Dijk and Fias (2011; but see also Previtali, Hevia, \& Girelli, 2009) using a WM task. The authors asked participants to remember in the correct order sequences of five random numbers (ranging from 1 to 10) displayed successively in the center of the screen. After this presentation phase, all numbers ranging from 1 to 10 were randomly and sequentially displayed in the center of the screen (twice each number). Participants had to execute an odd-even judgment but only for the five numbers that appeared in the presentation phase. After these judgments, four sequences of five numbers were presented, and participants had to indicate which of those sequences was the one presented in the presentation phase (also see third row of Fig. 1). The results showed that instead of having a classic SNARC effect, the left-hand responses were faster for the numbers presented in the first positions in the sequence displayed in the presentation phase (instead of the smaller magnitudes), and the right-hand responses were faster for the numbers presented in the last positions (instead of the larger magnitudes).

Since this study, several experiments (see Table 1 for an exhaustive list of experiments testing only the SPoARC or both the SPoARC and SNARC effects, ever since van Dijk \& Fias's, 2011, initial study) have been conducted. The SPoARC effect has been observed (1) with short-term memory (STM) paradigms necessitating only storage (see second row of Fig. 1; e.g., Guida, Leroux, Lavielle-Guida, \& Noël, 2016) and with WM paradigms necessitating storage and processing (e.g., van Dijck \& Fias, 2011); (2) when order is relevant for the task completion (such as in the van Dijck \& Fias, 2011, paradigm, in which participants have to recognize each sequence) or when order is irrelevant (i.e., without sequence recall or recognition; e.g., Guida, Leroux, et al., 2016); (3) with auditory (Guida, Leroux, et al., 2016) or visual input (e.g., van Dijck \& Fias, 2011); (4) with verbal material (e.g., Ginsburg et al., 2014; van Dijck \& Fias, 2011) or images (Ginsburg, Archambeau, van Dijck, Chetail, \& Gevers, 2017); (5) with open (Guida, Carnet, et al., 2018) or closed sets (e.g., van Dijck \& Fias, 2011); (6) with an eye-tracking device (Rinaldi, Brugger, Bockisch, Bertolini, \& Girelli, 2015); (7) with a line bisection task (Antoine, Ranzini,
Gebuis, van Dijck, \& Gevers, 2017); (8) when testing noncongenitally blind people, but not with the congenitally blind $^{1}$ (Bottini, Mattioni, \& Collignon, 2016); and (9) when testing Arabic literates, for whom the effect is reversed (Guida, Megreya, et al., 2018).

Umiltà, Bonato, and Rusconi (2018) have recently categorized SPoARC experiments as testing spatiotemporal associations because, in Westerners, the early items of a sequence are linked to left and the late to right. Although a sequential presentation of items has undeniably a temporal dimension, we do not think that time is a crucial dimension because in SPoARC experiments, participants do not have to execute a before/after judgment (e.g., was $\mathrm{X}$ item before $\mathrm{Y}$ item?), but just press a key if an item $\mathrm{X}$ was in the sequence, which does not stress the temporal dimension.

Finally, in several experimental conditions the SPoARC effect does not occur. First, no SPoARC effect was observed with sequences of 15 words (Guida, Carnet, et al., 2018), whereas it has been observed several times with sequences of four (Guida, Megreya, et al., 2018; van Dijck, Abrahamse, Majerus, \& Fias, 2013) or five (e.g., Ginsburg et al., 2014; van Dijck \& Fias, 2011) items. Second, the typical SPoARC effect does not seem to be observable with spatial sequences. Ginsburg et al. (2017) asked their participants to remember sequences of four black dots in an (invisible) $8 \times 8$ matrix; a SPoARC effect was subsequently tested, but no preferential association between the first positions of the sequences and the left hand and the last positions and the right hand was found. Third, Ginsburg et al. (2017) did not find a SPoARC effect with pseudowords, concluding that in order for the SPoARC effect to appear, information needed to be processed sufficiently deeply - namely, to a semantic level. We will come back to this conclusion in the section describing our expertise account.

\section{Theoretical accounts that explain both SNARC and SPoARC effects}

When the SNARC effect was first discovered, Dehaene et al. (1993) provided an LTM theoretical account of the effect putting forward the mental numerical line (MNL). They proposed that the SNARC effect was due to the representation numbers have in semantic memory that take the form of an MNL, its direction and orientation varying according to cultural reading habits. This LTM conception of the SNARC effect was also coherent with SNARC effects subsequently observed with nonnumerical ordinal sequences (e.g., the days of the week; Gevers, Reynvoet, \& Fias, 2004). In both cases (ordinal and

\footnotetext{
${ }^{1}$ Spatialization could be a purely spatial process or instead could be supported by visual processes. The fact that congenitally blind people do not exhibit a SPoARC effect, as compared to the noncongenitally blind, could indicate that visual processes are necessary at least at some point.
} 


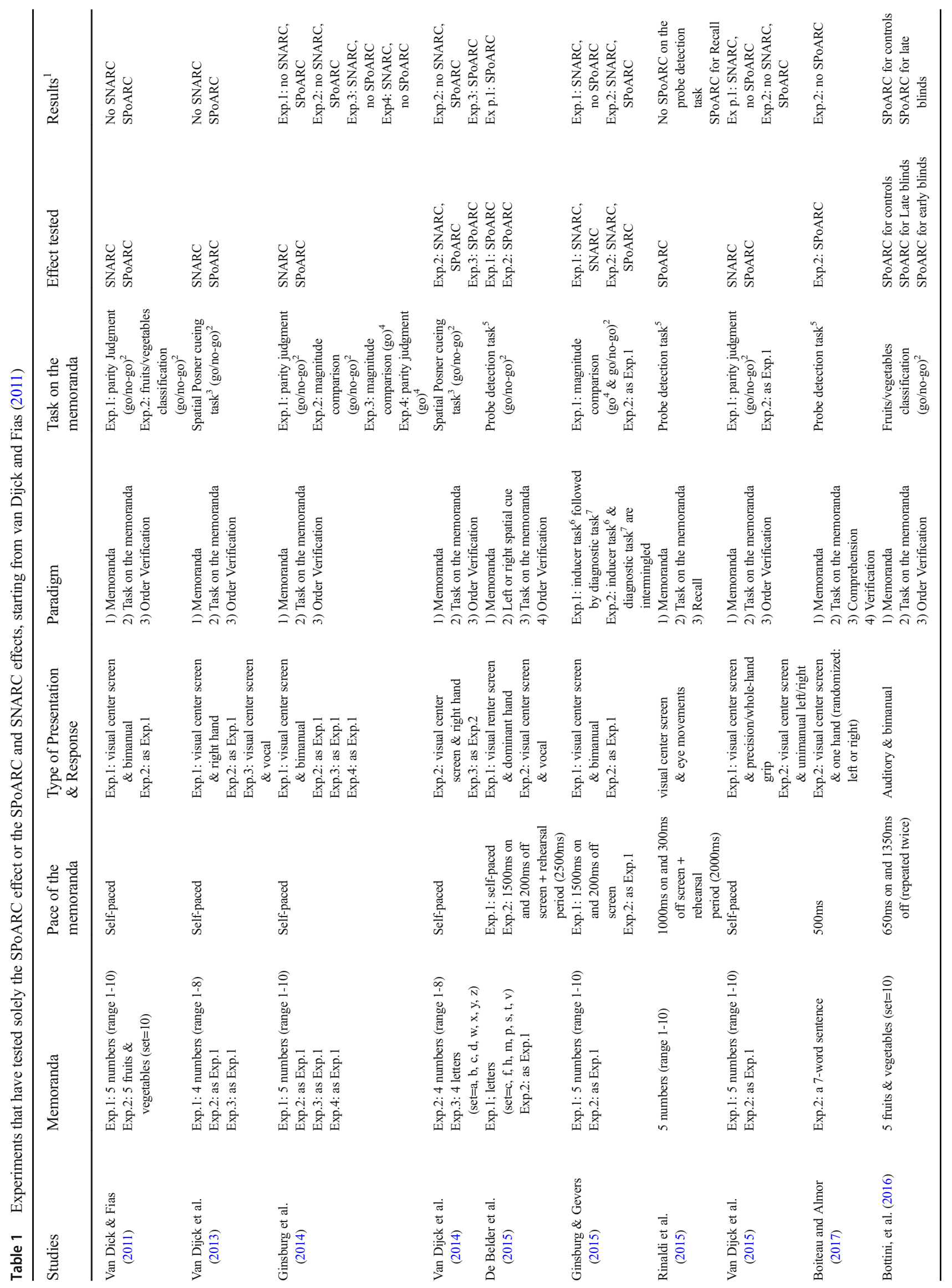




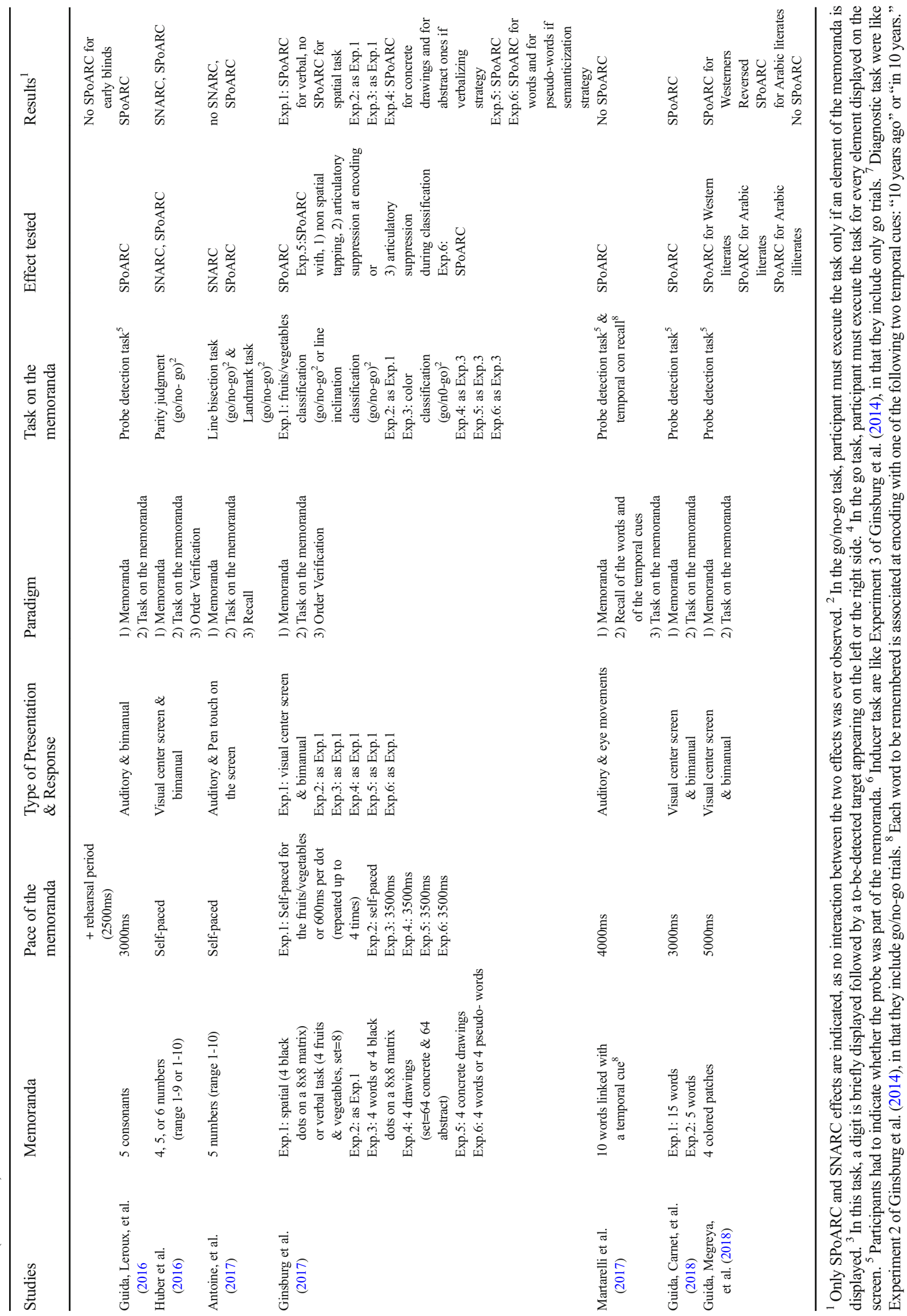


numerical sequences), the SNARC effect would be caused by the internal organization that these concepts have in LTM: that of a mental line.

\section{The working memory account of the SNARC and SPoARC}

effects The first account that encompassed both effects was proposed by van Dijck and Fias (2011) when they observed the SPoARC effect. To explain this effect, they could not use Dehaene et al.'s (1993) semantic LTM account, as their results showed a spatialization with random sequences, which do not exist in terms of numerical or ordinal sequences in semantic LTM. Their results pointed toward the idea that the participants created a mental line based on the order the items entered in WM, and not on the canonical order numbers have in semantic memory. Therefore, they proposed a WM account of the SPoARC, which was extended to the SNARC. The authors suggested that in both effects, position in WM is the determinant, as opposed to long-term memory (LTM) associations, and that the spatial coding of number does not have its origin in an LTM representation. ${ }^{2}$ Whereas Dehaene et al.'s (1993) semantic LTM account cannot explain the SPoARC effect, van Dijck and Fias (2011) argued that the WM account could explain the SNARC effect. For example, in a classic parity judgment SNARC task, once the participants know the range of the numbers used in the experiment (e.g., from 1 to 9), they will spontaneously start encoding the numbers in WM using the canonical order of numbers. Since the positions in WM are associated with space, small numbers would thus acquire a left value, and large numbers a right value, throughout the task.

Although van Dijck and Fias (2011) pitted a long-term representation account against a WM account, the WM account does not deny the importance of LTM knowledge in the SNARC and SPoARC effects. This is apparent in later versions of the account (i.e., the mental whiteboard ${ }^{3}$; Abrahamse, van Dijck, \& Fias, 2016, 2017; Abrahamse, van Dijck, Majerus, \& Fias, 2014), in which the role of LTM knowledge is more explicitly stated. Abrahamse et al. (2016) indicated that LTM knowledge intervenes at least at three levels. First, spatialization occurs because the incoming information in WM acquires a spatial value by being linked to a spatial LTM template (the mental whiteboard), such that spatial attention controls later search and selection. Second, numbers trigger an orientation in WM that depends on the direction of one's reading/writing system. Third, "LTM contains-

\footnotetext{
$\overline{2}$ Van Dijck and Fias (2011, p. 115) wrote: "To distinguish between position in working memory and long-term memory associations as determinants of the SNARC effect we designed two experiments. . . If the spatial coding of numbers has its origin in a long-term representation, a regular SNARC effect is expected. If on the contrary, the SNARC effect is the result of positional coding in WM, numbers should be spatially coded according to their position in the WM."

${ }^{3}$ The authors tend to use the term "WM account" when writing about the SNARC effect, and "mental whiteboard" when writing about serial order.
}

besides item representations - a representation for ordered item sets that are used frequently and systematically" (i.e., 1-9; Abrahamse et al., 2016, p. 4).

The dual account of the SNARC and SPoARC effects Following van Dijck and Fias's (2011) proposal, several studies have tested their WM account. Ginsburg et al. (2014) first showed that if van Dijck and Fias's paradigm was tweaked, a SNARC effect would replace the SPoARC effect. In the original paradigm (i.e., van Dijck \& Fias, 2011) presented above, participants must classify numbers only if they belong to the memoranda (i.e., the five numbers that appear in the presentation phase). The result is generally a SPoARC effect with no SNARC effect. However, in Experiments 3 and 4, Ginsburg et al. (2014) removed the no-go component by asking the participants to classify all the numbers displayed on the screen. And the result was a SNARC effect with no SPoARC effect. Because the two effects do not seem to be sensitive to the same task demands, the authors used their results to counter the idea that the SPoARC and SNARC effects were due to the same underlying processing mechanism, as claimed by the WM account.

However, the result that really laid the ground for the dual account as a counterproposal to the WM account came from Ginsburg and Gevers's (2015) study. With an astute paradigm that intermingled go/no-go and go trials (for more details, see the Accounting for the Data section describing our expertise model), they showed that SNARC and SPoARC could coexist (for a similar result, also see Huber, Klein, Moeller, \& Willmes, 2016) and therefore were not mutually exclusive (and no interaction was detected). Ginsburg and Gevers proposed that the SNARC and SPoARC effects derive from two different processes, the former based on LTM semantic knowledge (with numbers ordered canonically) and the latter based on the order items entered in WM. The dual nature of the effects was the reason why both effects could be detected conjointly. These results are difficult to account for with a pure WM account, because one would expect only one order of numbers to be in WM during the task: either the numbers ordered canonically or the numbers as they entered WM (for more details, see the Accounting for the Data section).

\section{Expert memory}

If the idea derived from the SPoARC effect (i.e., verbal items in WM are spatially organized) could seem new in the numerical cognition domain and even for classic theories of WM in which visuospatial information is separated from verbal information (Baddeley, 1986; Baddeley \& Hitch, 1974; but see Baddeley, 2000), it is not new to mnemonists. Indeed, the allegedly most ancient memory technique (mnemonic) - the method of loci proposed by Simonides of Ceos more than 
two millennia ago (Worthen \& Hunt, 2011; Yates, 1966) involves organizing information spatially. Before a speech, Greek orators visualized a well-known route or a sequence of familiar locations (e.g., rooms in one's own house), and mentally stored important words of the speech in different locations. Then, during the speech, orators would mentally picture their house, taking a mental tour and retrieving each word from familiar locations (e.g., rooms). This method clearly necessitates to spatialize the items to be remembered in various locations. The method of loci is still being used nowadays by expert mnemonists in World Memory Championships.

We believe that the concepts and findings from the domain of memory expertise can shed light on both the SNARC and SPoARC effects, not only because of the spatial connection between memory expertise and these effects but also because reading/writing expertise seems to play a role in both effects. In effect, the SNARC/SPoARC direction varies according to the reading/writing direction (e.g., Guida, Megreya, et al., 2018; Shaki et al., 2009) and illiterates do not seem to exhibit any SNARC or SPoARC effect (e.g., Guida, Megreya, et al., 2018; Shaki, Fischer, \& Göbel, 2012; Zebian, 2005). Hereafter, we will succinctly introduce the expert memory domain.

\section{Capturing memory expertise in the lab}

Chase and Ericsson (1981, 1982, Ericsson, Chase, \& Faloon, 1980) trained in their laboratory two university students (S.F. and D.D.) to increase their performance in a digit memory task from a standard score of seven digits to 82 digits in $264 \mathrm{~h}$ of training (S.F.) and to 106 digits after $800 \mathrm{~h}$ of training (D.D.). In the task, a list of digits was presented at a rate of one digit per second, and the participants had to recall the correct sequence. The theoretical accounts shown below were based on these findings.

\section{Theoretical accounts of expert memory}

EPAM IV EPAM (Elementary Perceiver and Memoriser) IV (Richman, Staszewski, \& Simon, 1995) is a computational model with a STM that can hold a limited number of chunks, a semantic LTM accessed from a discrimination net, and production rules. Both LTM and the discrimination net grow due to the functioning of learning processes stored in LTM. One important type of structure within its LTM is the retrieval structure, which is a specific net of nodes with their connecting links forming a treelike structure. New information (e.g., a sequence of digits) can be stored at different nodes (a.k.a. slots) of the retrieval structure. With experience or training the retrieval structure can also grow, allowing more pieces of information to be stored in their slots. Several retrieval structures can be grown in EPAM IV's LTM.

D.D.'s performance was explained by two components of EPAM IV: the use of retrieval structures to store groups of digits, and the use of semantic knowledge of running times. D.D. was a runner, so he possessed semantic knowledge of running times (e.g., the sequence of digits "9 58 " can be represented by the label "Usain Bolt's $100 \mathrm{~m}$ world record," which is $9.58 \mathrm{~s}^{4}$ ). Semantic knowledge enables the chunking of information, thus separate elements can be processed as one unit ("9 58 " are processed as one element "9.58").

Long-term working memory Before the long-term working memory (LTWM) theory (Ericsson \& Kintch, 1995), Ericsson and colleagues (Chase \& Ericsson, 1981, 1982) proposed the skilled memory theory and put forward three principles to explain how people without exceptional memory capacity could show exceptional performance in memory tasks. The first principle "meaningful encoding" states that for information to be stored effectively in LTM, it needs to be transformed into meaningful units through the knowledge one possesses (i.e., semantic knowledge), like what occurs in chunking for example. The second principle (structured retrieval) proposes that by building and using a retrieval structure one can store and access information more efficiently. The third principle (acceleration) states that, with extensive practice, experts can accelerate the encoding and retrieval of information in LTM. Figure 2 shows the evolution of the spatial structure that S.F. used as a retrieval structure. Like D.D., S.F. used his semantic knowledge to chunk together one-digit numbers as running times and link them to the slots of his retrieval structure.

Ericsson and Kintsch (1995; see also Ericsson \& Delaney, 1999) built upon Chase and Ericsson's $(1981,1982)$ skilled memory theory and developed the LTWM theory. One new structure that Ericsson and Kintsch (1995, p. 220) included is an elaborated memory structure "associating items from a given trial or context," which means, when considering Fig. $2 b$, that on top of the retrieval structure, experts can create meaningful encodings between chunks that allow for distinguishing a trial from previous ones. ${ }^{5}$

Whereas the skilled memory theory was meant to explain the performances of DD or SF, LTWM was proposed as an explanation for the memory involved in all domains of expertise. LTWM is domain-specific, and it is acquired to improve performance in specific tasks that require large WM demands. Although there are several differences between EPAM IV and LTWM (mainly, EPAM IV is implemented in a computational model, whereas LTWM is not), their main components are the same: retrieval structures and domain-specific semantic knowledge. For example, to explain memory performance in

\footnotetext{
${ }^{4}$ We use Usain Bolt's world record as a memorable example. D.D. did not use Usain Bolt's world record.

${ }^{5}$ An example of an elaborated memory structure is the creation of a link between "3 298 " (3 $\min 29.8 \mathrm{~s})$ and "1 413 " (1 $\min 41.3 \mathrm{~s})$ as they are both excellent running times for two close distances $(1,500 \mathrm{~m}$ and $800 \mathrm{~m}$, respectively). For the interested reader, Guida et al. (2012, p. 224) provided a figure that completes Fig. $2 b$ in terms of this elaborated memory structure.
} 
a

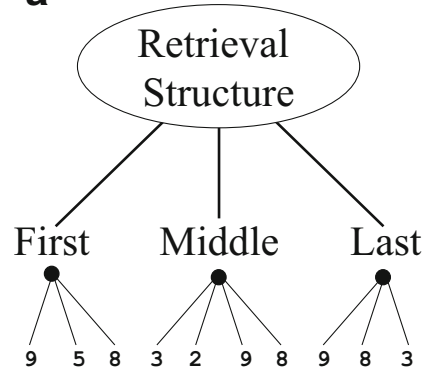

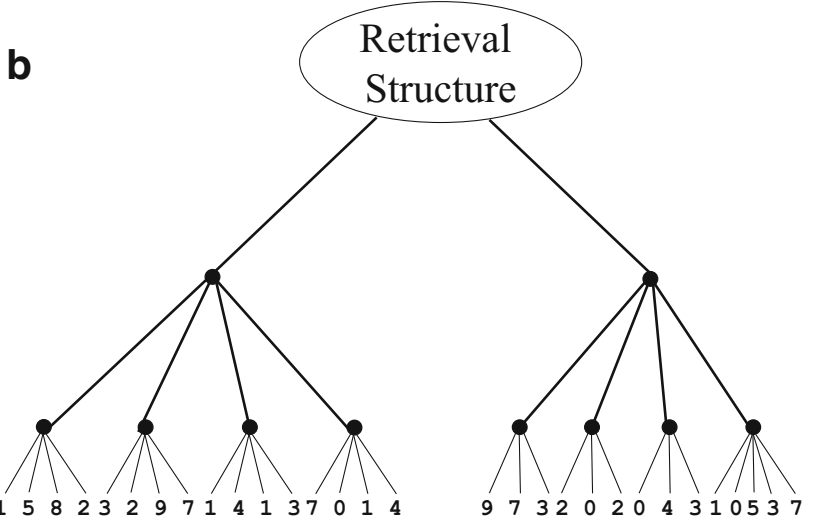

Term Working Memory," by K. A. Ericsson and W. Kintsch, 1995, Psychological Review, 102, pp. 211-245. Copyright 1995 by the American Psychological Association

by K. A. Ericsson, 1985, Canadian Journal of Psychology, 39, pp. 188231. Copyright 1985 by the American Psychological Association. (b) S.F.'s retrieval structure to recall 30 one-digit numbers. From "Long-

chess players, LTWM theory suggests that chess players use a representation of an empty chessboard as a retrieval structure. Likewise, for comprehending texts, items (words) are remembered better when the readers are able to form a situational model (for a detailed explanation, see van Dijk \& Kintsch, 1983). The situational model is a complex structure that combines an idea of the topics and temporal cues in the text (like a retrieval structure) with semantic information (knowledge of words), and it is used by readers to remember critical components of a text to be able to comprehend it. Waiters can memorize orders by generating retrieval structures (e.g., the locations of the tables across the restaurant) and storing information within those structures. Medical experts generate retrieval structures, which include medical knowledge, and they are associated with specific information about patients (symptoms, laboratory test results, etc.).

Template theory In LTWM and EPAM IV, retrieval structures and semantic knowledge are separated. The template theory developed by Gobet and Simon (1996) to explain memory in chess introduces a different structure - the template (for a detailed discussion of the differences between retrieval structures and templates, see Ericsson \& Kintsch, 2000; Gobet, 2000). The templates have characteristics of both retrieval structures and semantic knowledge, and they evolve from more simple structures - chunks. Chunks are a meaningful group of individual items. By their accumulated experience, chess experts' memory evolves chunks (configurations of three or four chess pieces) into templates (configurations of more than ten chess pieces). The difference between chunks and templates is not only their size but also that templates contain slots in which additional information (including small chunks) can be stored. The core of the template is not an empty structure; rather, it contains domain-specific knowledge (like the semantic knowledge in EPAM IV and LTWM) as well as slots (like retrieval structures). Figure 3 shows an example of a template: The pieces on the board indicate the core, whereas the crosses indicate the positions where chess pieces can be added without changing the identity of the template (i.e., the slots).

\section{Synthetizing and generalizing expert memory to everyday memory}

Semantic knowledge and retrieval structures are the backbone of EPAM IV and LTWM, whereas chunks and templates constitute the core of the template theory. Despite their differences, the three theories evolve with regard to common principles, which were identified by Guida and colleagues (Guida, Campitelli, \& Gobet, 2016; Guida, Gobet, \& Nicolas, 2013; Guida et al., 2012). Building on their work, we propose the general term of "knowledge structure," which refers to the meaningful blocks of knowledge that one builds while acquiring expertise. These knowledge structures can be of two types: non slotted schemas (e.g., semantic knowledge, chunks) or slotted schemas (e.g., retrieval structures, templates)

In addition, Campitelli (2015) proposed that slotted schemas such as retrieval structures are not only important for experts, but they are at the core of memory mechanisms for everyday life. He used the term "knowledge structures" to emphasize that they are involved in many cognitive processes, not only in memory retrieval. In this approach, humans use the most relevant available knowledge structures to assist them in remembering and processing information. If the task at hand and the information to be remembered belong to a domain in which we have expertise, we can use domain-specific and content-rich slotted schemas that we have developed while being exposed to that domain, similar to templates (e.g., a configuration of chess pieces, a typical sentence, the configuration of our house to be used in the loci method). In typical laboratory memory tasks with meaningless material, we do not have expertise, thus we will use slotted schemas with a 
Template-core:

White $8 \mathrm{c} 4,8 \mathrm{~d} 5,8 \mathrm{e} 4,8 \mathrm{f} 2,8 \mathrm{~g} 2, \mathrm{~g} 1,4 \mathrm{c} 3$, 鼻 $\mathrm{e} 2$

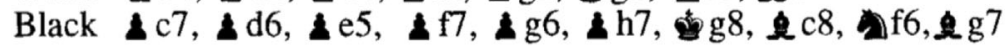

Slot for pieces:

$$
\begin{array}{ll}
8 & : \mathrm{h} 2, \mathrm{~h} 3 \\
\mathbf{8} & : \mathrm{a} 7, \mathrm{a} 5 \\
\mathbf{8} & : \mathrm{b} 8, \mathrm{~d} 7, \mathrm{c} 5 \\
\mathbf{4} & : \mathrm{c} 2, \mathrm{~d} 1 \\
\mathrm{G} & : \mathrm{c} 1, \mathrm{~d} 2, \mathrm{e} 3
\end{array}
$$

Slot for squares:

$$
\begin{aligned}
& \text { d2: } \quad \text {, } 9 \text {, empty } \\
& \text { e8: } \quad \mathbf{E}, \mathbf{1} \text {, empty } \\
& \text { el: 笪, 包, empty }
\end{aligned}
$$

Slot for opening: King's Indian Defense

Slot for plans: $\quad$ Break in the center with $\mathrm{f} 7 \mathrm{f} 5$

Slot for moves: 1 ... Nf6-e8

$$
\text { 1... Nf6-h5 }
$$

Links to other templates: chunk \#231

Fig. 3 Example of a template from Gobet and Simon (1996). On the left are the attributes of the template: the nonvariable part of a template (the template core) and the variable part of a template (slots for pieces, squares, openings, plans, moves, and links to other templates). On the right is a diagrammatic representation of the same template: Pieces on the

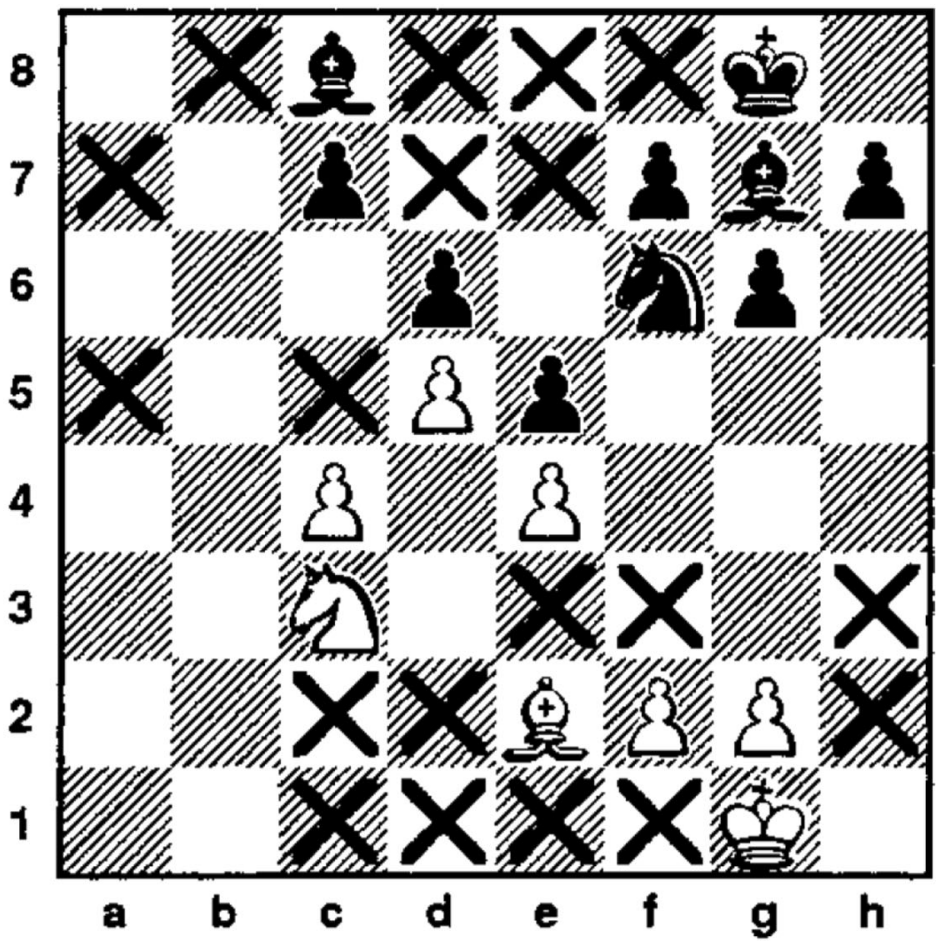

board indicate the core pieces in the template, and crosses indicate values contained in the piece or square slots. From "Templates in Chess Memory: A Mechanism for Recalling Several Boards," by F. Gobet and H. A. Simon, 1996, Cognitive Psychology, 31, pp. 1-40. Copyright 1996 by Academic Press. Adapted with permission generic core, like for example the retrieval structure first used by SF when he started to train (Fig. 2a). This is similar to the slotted structures proposed in traditional STM models (e.g., Luck \& Vogel, 1997). Campitelli proposed that the traditional models of STM constitute only one of many possible knowledge structures that we can use for remembering information.

Previous models grounding working memory in long-term memory knowledge Although we characterize everyday memory borrowing concepts from the domain of memory expertise and using them to account for two spatial effects that occur in $\mathrm{WM}$, we do not want to minimize the importance of other types of LTM knowledge that are known to be activated in WM and to contribute to WM performances through LTM-WM interaction.

Indeed, the most influential theories of WM are built around the link between LTM and WM, postulating that WM is the activated portion of LTM (e.g., Anderson, Reder, \& Lebiere, 1996; Barrouillet, Bernardin, \& Camos, 2004; Cowan, 1995; Just \& Carpenter, 1992; Oberauer, 2002). In these "LTM-based WM models" (Guida et al., 2013) - in contrast with models based on Baddeley and Hitch's (1974) architecture, in which
WM and LTM are envisaged as separated entities (but see Baddeley, 2000) - WM performances are interpreted in terms of LTM activation or through the process of reconstructing LTM activation from LTM knowledge (Schweickert, 1993; or the reconstruction hypothesis of Towse, Cowan, Hitch, \& Horton, 2008). Among the advantages of "LTM-based WM models" is the fact that the link between WM and LTM facilitates the accounts of numerous studies that have demonstrated the effects of LTM knowledge on WM (for an exhaustive list, see Majerus, 2008). For example, word lists are recalled better than nonword lists (e.g., Hulme, Maughan, \& Brown, 1991), words of high lexical frequency are recalled better than less frequent words (e.g., Roodenrys, Hulme, Alban, Ellis, \& Brown, 1994), and lists of concrete words are recalled better than lists of abstract words (e.g., Walker \& Hulme, 1999). These results clearly show that verbal WM strongly relies on the activation of LTM linguistic structures, moreover in a very fast and automatic manner (Kowialiewski \& Majerus, 2018; Majerus, Van der Linden, Mulders, Meulemans, \& Peters, 2004). Hence, it comes as no surprise that some WM models have grounded WM in terms of linguistic knowledge. Martin 
and Saffran (1992) is one of the most extreme examples, in that they viewed verbal STM as an emergent property of the activation of phonological, lexical, and semantic language representations in the language network (see also Burgess \& Hitch, 1999; Gupta, 2003). A more recent proposal, the attention, order, short-term memory activation model (Majerus, 2008; Majerus, Heiligenstein, Gautherot, Poncelet, \& Van der Linden, 2009) hybridizes Martin and Saffran's model with more modern views concerning the importance of serial order (e.g., Burgess \& Hitch, 1999), adding the proposal of an attentional modulator that can direct resources toward either language representations or item processing. Acheson and MacDonald's (2009a; see also Acheson \& MacDonald, 2009b) account of WM also heavily relies on linguistic knowledge, but this time in terms of production. They proposed that maintaining serial order in verbal WM may emerge from the language production architecture (i.e., language production hypothesis).

Overall, it should be clear that it is well-known that LTM knowledge aids memory and that the interaction between LTM knowledge and WM is a pervasive feature of modern models of WM. What our proposal suggests, in terms of novelty, is a further instantiation of this interaction, by proposing that knowledge structures as a generalization of concepts from theories of expertise can also explain everyday memory performance such as that implicated in the SPoARC and SNARC effects.

\section{Accounting for both SNARC and SPoARC effects: An expertise account}

\section{Nonslotted schemas: The SNARC effect}

Taking an example from the chess game, if a player starts playing consistently, he will increase his knowledge of the game, he will start remembering the game positions (or part of the positions) that are often played. And gradually, individual pieces that compose a position will cement into chunks. Once a player has built and stored these nonslotted schemas in LTM-transitioning from the chunk creation to the chunk retrieval phase (Guida et al., 2012) — he will be able to use them to encode information. This explains why STM capacity is a function of our capacity to chunk information (Cowan, 2001, 2012; Mathy \& Feldman, 2012).

How do they apply to the SNARC effect? These nonslotted schemas can be used to explain SNARC-like effects. Like chess players who are exposed to chess piece configurations, laypeople are usually exposed to numbers, process during which they gradually learn that numbers have a precise order. And some orders are highly practiced, such as the sequence 123 or the sequence $1-10$. We suggest that very practiced sequences will behave as chunks and thus can be considered nonslotted schemas that can be directly activated from LTM. The exact identity of these sequences will vary as a function of expertise with numbers (see below for professional mathematicians). But for an average young adult, the canonical 1-9 number set (Abrahamse et al., 2016) will certainly be available as a chunk and will thus be used as a nonslotted schema. We believe that the same kind of nonslotted schemas are in use when one is processing the days of the week, the months of the year, or the alphabet. Hence, when participants are confronted with SNARC-like tasks, they will activate these nonslotted schemas or a portion of them

Like the MNL, these nonslotted schemas also include the spatial nature of these sequences. This kind of spatialization can be easily comprehended, especially in terms of grounded cognition (e.g., Barsalou, 2010; Glenberg, 1997; Shapiro, 2011); if one always experiences months or numbers as sequences written from left to right, it is comprehensible that when one thinks about months or numbers, the left-to-right dimension could still be associated. The idea of nonslotted schemas to explain the SNARC effect is not far from Dehaene's LTM account of SNARC (MNL), the main difference being that our account stresses expertise. SNARC-like effects start to be detected in four-year-old children (McCrink, Shaki, \& Berkowitz, 2014; Opfer, Thompson, \& Furlong, 2010), therefore it seems that the kind of expertisefor this spatialization to appear-occurs by means of observational learning (for a review see McCrink \& Opfer, 2014; Patro, Nuerk, Cress, \& Haman, 2014) through the interaction between infants and caregivers (McCrink, Caldera, \& Shaki, 2018) via storybook reading for example. In cultures in which numbers (left to right in Israel) and words (right to left in Israel) are written in opposite directions, nonslotted schemas seem less or not at all spatialized (Shaki et al., 2009), which suggests that for SNARC-like effects to be observed, the spatial biases in a culture must not be opposite to each other. Finally, concerning the relation between expertise and SNARC effect, recent work (Cipora et al., 2016; Kramer, Bressan, \& Grassi, 2018) suggests that it could be quadratic, as the link between mathematical knowledge and the SNARC effect is positive in children but seems to be negative in adults. Different processing/ representations could be engaged in professional mathematicians: Cipora et al. proposed nonlinear/nonhorizontal numerical representations or more abstract ones, which would correspond to different knowledge structures within our framework.

\section{Slotted schemas: The SPoARC effect}

As we presented above, when a player increases his knowledge, he will be able to use nonslotted schemas to encode information. However, if he continues increasing his knowledge, he will start developing slotted schemas, named templates (Gobet \& Simon, 1996; also see Gobet, 2013; Gobet et al., 2001) 


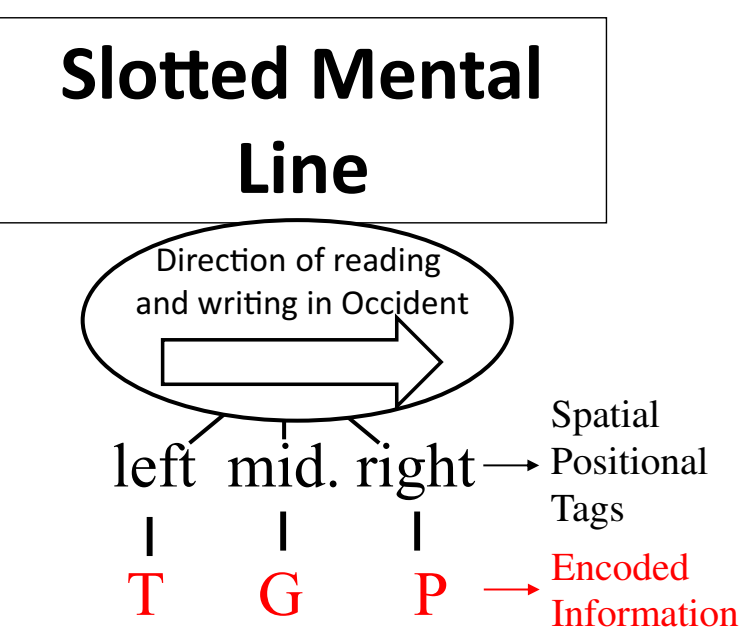

Fig. 4 The slotted mental line used by Westerners to encode three elements through spatial positional tagging. Adapted from "2011 Space Odyssey: Spatialization as a Mechanism to Code Order Allows a Close Encounter Between Memory Expertise and Classic Immediate Memory Studies," by A. Guida and M. Lavielle-Guida, 2014, in Psychological Perspectives on Expertise (pp. 176-180), Frontiers Media SA. Copyright 2014 by the authors

How do they apply to the SPoARC effect? Similarly, if an individual increases his expertise by completing his formal training in reading/writing, we suggest that a slotted schema is developed (see also Guida \& Lavielle-Guida, 2014), since Guida, Megreya, et al. (2018) did not observe the SPoARC effect with illiterates. This slotted schema takes the form of a mental line. However, unlike the MNL, it is a slotted mental line. As is shown by Fig. 4, the elements entering WM will be associated to it, and therefore their position in WM will be marked/tagged spatially. The slotted mental line can be envisioned as a primitive version of S.F.'s slotted schema pictured in Fig. 2a. However, contrary to a fully grown slotted schema (e.g., Fig. 2b), the slotted mental line does not offer the possibility to transfer information rapidly to LTM. ${ }^{6}$

This idea of a slotted mental line fits well with recent computational models of WM and how they account for order coding. Since the seventies, results (e.g., Bjork \& Healy, 1974; Dale, 1987; Engelkamp \& Dehn, 2000; Henson, Hartley, Burgess, Hitch, \& Flude, 2003; Majerus, Poncelet, Elsen, \& van der Linden, 2006; Mulligan, 1999; Sperling \& Melchner, 1976) have shown that WM models should account for two distinct kinds of information: memory for the content and memory for the order, which seem to be coded and represented separately (for a review, see Hurlstone, Hitch, \& Baddeley, 2014; Majerus \& Attout, 2018; Marshuetz, 2005).

\footnotetext{
${ }^{6}$ One of the hallmarks of experts' retrieval structures is to enable a fast transfer of information into LTM (see for more details, Ericsson \& Kintch, 1995; Gobet, 2000). However, this acceleration principle is effective only in case of specific training (e.g., SF or the method of loci), which is not undertaken by laypeople who just rely on the slotted mental line.
}

The type of models that account very well for this dissociation (content/order) and that have become predominant in the last two decades are positional models (e.g., Anderson \& Matessa, 1997; Brown, Neath, \& Chater, 2007; Brown, Preece, \& Hulme, 2000; Oberauer \& Lewandowsky, 2011; Portrat, Guida, Phénix, \& Lemaire, 2016). In these models, order is coded through positional tags associated to each item. Even if no consensus has emerged concerning the actual nature of the positional tags, recent work on spatialization (e.g., Ginsburg et al., 2017; Guida, Carnet, et al., 2018; Guida, Leroux, et al., 2016; Rinaldi et al., 2015; van Dijck, Fias, \& Andres, 2015) has showed that their nature could be spatial (see also Rinaldi, Merabet, Vecchi, \& Cattaneo, 2018), like in the mental slotted line we are proposing.

Interestingly, literacy is not the only expert-related condition to be able to use the mental slotted line. As was recently shown by Ginsburg et al. (2017), the encoded information needs to be processed deeply enough at a semantic level for an individual to be able to use his mental slotted line. This result is interesting in terms of expertise as it parallels the first principle of the skilled memory theory (Chase \& Ericsson, 1981, 1982), which states that in order to be able to use the skilled memory, a meaningful encoding is necessary.

\section{Difference between the expertise account and previous ones}

The central element that the WM account and our account have in common is the LTM cognitive structure that is activated when one must encode a sequence of verbal elements as in SPoARC tasks. The WM account (Abrahamse et al., 2016, p. 4) proposes that "each item is bound to a specific coordinate within an existing, well-coordinated template ${ }^{7}$ from long-term memory." Building on work we published previously (Campitelli, 2015; Guida \& Lavielle-Guida, 2014), we have also proposed an LTM structure (i.e., a slotted schema). Therefore, as far as the SPoARC effect is concerned our explanation is similar to the WM account even if our LTM structures have features derived from the theories of expertise, which is no the case for the WM account.

However, it is when accounting for the SNARC effect that our views really diverge. The WM account suggests that in the SNARC effect too, spatialization occurs in WM and depends on the same LTM template than in the SPoARC effect. Drawing from the literature on expertise, we have put forward a nonslotted schema to account for the SNARC.

To be more specific, in a SNARC task, in which elements from 1 to 9 are used, and as far as the WM account is concerned, only these numbers and their canonical order will be activated from LTM, no spatial value will be activated from

\footnotetext{
${ }^{7}$ The term "template" used by Abrahamse et al. (2016) is not related to Gobet and Simon's (1996) templates.
} 
LTM, the spatial value will be added when they interact with the LTM template in WM. For our account, the number set 1-9 will be activated from LTM as a nonslotted schema, which also contains their spatial value, similarly to the MNL account. It seems to us more economical for the cognitive system to use the spatial information already linked to numbers (or in other highly known sequences; e.g., the days of the week) and putatively stored in LTM, than to (re)spatialize the information when it reaches WM as suggested by the WM account. We believe that the cognitive system will spatialize information in WM as a last resort. Hence, we introduce here the three parsomony steps of our account. First, if spatial information is already provided by the task at hand, the system will just use the spatial information in the environment. Recent results show that we do not respatialize information if it is already spatialized. Guida, Abrahamse, and van Dijck (in revision) showed that if the information is presented to Westerners from right to left, they will not respatialize it from left to right, but just use the spatial information that is provided (for other examples, see the Simon effect [Simon \& Rudell, 1967] or the visuospatial bootstrapping effect [Darling, Allen, \& Havelka, 2017; Darling, Allen, Havelka, Campbell, \& Rattray, 2012; Darling \& Havelka, 2010]). Second, if the task does not provide spatial information, the cognitive system will use the spatial information in LTM, if any is available (i.e., nonslotted schemas; e.g., the SNARC effect). Third, if this LTM spatial information is not suitable to code the information (e.g., a random sequence of numbers), the cognitive system will use a slotted schema to spatialize the information.

Concerning the dual account as compared to our own, there are many converging points, but also some differences. The main convergence is that the dual account explains the SNARC and SPoARC effects separately, by invoking two mnemonic systems to account for them: LTM for SNARC and WM for SPoARC. In our account, too, the SNARC and SPoARC effects are accounted for separately, but not by invoking two memory systems; instead, we invoke two different LTM structures: nonslotted and slotted schemas. The second crucial point is that in our account, the capacity to use LTM is a function of expertise.

Table 2 summarizes the three accounts and how they explain the SNARC and SPoARC effects.

\section{Accounting for the data}

When putting forward theories or hypotheses, an important concern is how these theories can account for the data, or inversely, do the data adjudicate between the different theories?

The first interesting pattern of results is that the SPoARC effect does not seem to operate on sets bigger than six (usually four or five; Guida, Carnet, et al., 2018). Data from Huber et al. (2016) suggest that the SPoARC effect decreases gradually when transitioning from sequences of four to five to six. The SPoARC effect could be limited by standard STM/ WM limitations, which do not seem to apply to SNARC - it can be observed, for example, with a range of ten numbers (e.g., 0 to 9 in Dehaene et al., 1993).

From a dual-account perspective, this discrepancy could indicate that two different memory systems are differentially involved (LTM vs. STM/WM), which do not have the same limitations. From a WM account this would maybe be more difficult to explain, and to our knowledge Abrahamse and colleagues have not addressed this discrepancy.

From our perspective the explanation resides in the fact that two different structures are operating. Concerning the SNARC, the nonslotted schemas (e.g., the sequence 1 to 9) will behave as chunks and chunks allow to compress (e.g., Mathy \& Feldman, 2012) various elements (e.g., F, B, I) into one (e.g., FBI), which allow to overcome the standard limits of STM/WM (Chase \& Simon, 1973; de Groot, 1965). Hence, the SNARC effect is not limited by the standard STM/WM limitations.

Concerning the SPoARC effect, in our framework it makes sense that it is linked with standard STM/WM limits, as we believe that STM/WM capacities depend (among various elements) on the capacity to use the mental slotted line. For example, illiterates who putatively do not use the slotted mental line, have lower STM/WM capacities (Demoulin \& Kolinsky, 2016; Kosmidis, Zafiri, \& Politimou, 2011; Silva, Faísca, Ingvar, Petersson, \& Reis, 2012). Since both the SPoARC effect and STM/WM capacities depend (among other factors) on the slotted mental line, it comes as no surprise within our framework that the SPoARC effect and STM/WM capacities are tied together. ${ }^{8}$

The second pattern of results concerns Ginsburg and Gevers's (2015) and Huber et al.'s (2016) results. Contrary to van Dijck and Fias (2011) and previous experiments (e.g., Ginsburg et al., 2014), Ginsburg and Gevers (2015) and Huber et al. (2016) observed both SNARC and SPoARC effects (but no interaction). Both studies used a paradigm similar to that of van Dijck and Fias: A sequence of numbers was displayed and had to be remembered, and then a classification task was administrated in which participants had to classify (e.g., by a left keypress for odd numbers and a right keypress for even numbers) each number displayed, but only if it belonged to the memoranda (third row of Fig. 1). There were

\footnotetext{
${ }^{8}$ Crucially one could ask why should the SPoARC effect be tied to STM/WM limitations while the SNARC is not? After all, STM/WM capacities are also function of chunking (Cowan, 2001; Mathy \& Feldman, 2012) and chunks (i.e., nonslotted schemas) are supposed to determine SNARC, too. The answer is that chunks used in the SNARC effect (e.g., the sequence 1 to 9) do not have a general use as they cannot be used to chunk information in a span task, which does not contain (purposely) sequences with canonical sets of numbers, hence the SNARC effect is decorrelated from the standard STM/WM limitations. Conversely the mental slotted line has a general application (to random orders of numbers, letters, words . . .) that can be used in a span task, hence the tie between SPoARC and STM/WM limitations.
} 
Table 2 Dual account, working memory account, and expertise account of the SNARC and SPoARC effects

\begin{tabular}{|c|c|c|c|}
\hline & Dual account & Working memory account & Expertise account \\
\hline $\begin{array}{l}\text { General } \\
\text { feature }\end{array}$ & $\begin{array}{l}\text { Spatialization in the SNARC is due to LTM associations } \\
\text { between numbers and space (i.e., MNL) and } \\
\text { spatialization in the SPoARC is due to temporary } \\
\text { bindings between items within our mental space in } \\
\text { WM. }\end{array}$ & $\begin{array}{l}\text { Spatialization is due to an interaction } \\
\text { between items and an LTM template } \\
\text { and emerges in WM. }\end{array}$ & $\begin{array}{l}\text { Spatialization is due to two LTM knowledge } \\
\text { structures: non slotted schemas in the } \\
\text { SNARC and slotted schemas in the } \\
\text { SPoARC. }\end{array}$ \\
\hline $\begin{array}{r}\text { SNARC } \\
\text { effect }\end{array}$ & $\begin{array}{l}\text { - Content comes from LTM } \\
\text { Numbers belong to semantic memory } \\
\text { - Order of the content comes from LTM } \\
\text { Numbers have an order in semantic memory } \\
\text { - Associations between content and space come from } \\
\text { LTM } \\
\text { Numbers have a spatial value on the MNL }\end{array}$ & $\begin{array}{l}\text { - Content comes from LTM } \\
\text { Numbers belong to semantic memory } \\
\text { - Order of the content comes from LTM } \\
\text { Numbers have an order in semantic } \\
\text { memory } \\
\text { - Associations between content and } \\
\text { space are created in WM but the } \\
\text { spatial values come from an LTM } \\
\text { structure } \\
\text { Numbers are given their spatial value } \\
\text { in WM when they interact with an } \\
\text { LTM template which is spatial in } \\
\text { nature }\end{array}$ & $\begin{array}{l}\text { - Content comes from LTM } \\
\text { Numbers belong to semantic memory } \\
\text { - Order of the content comes from LTM } \\
\text { Numbers have an order in nonslotted } \\
\text { schemas, which are expertise-depended } \\
\text { - Associations between content and space } \\
\text { come from LTM } \\
\text { Sequence of numbers that are practiced form } \\
\text { nonslotted schemas in LTM, in which } \\
\text { numbers have a spatial value }\end{array}$ \\
\hline \multirow[t]{2}{*}{$\begin{array}{c}\text { SPoARC } \\
\text { effect }\end{array}$} & $\begin{array}{l}\text { - Content comes from LTM } \\
\text { Items belong to semantic memory } \\
\text { - Order of the content is created in WM } \\
\text { Items order is given by their position in WM }\end{array}$ & $\begin{array}{l}\text { - Content comes from LTM } \\
\text { Items belong to semantic memory } \\
\text { Order of the content is created in WM } \\
\text { Items order is given by their position in } \\
W M\end{array}$ & $\begin{array}{l}\text { - Content comes from LTM } \\
\text { Items belong to semantic memory } \\
\text { - Order of the content is created in WM } \\
\text { Items order is given by their position in WM }\end{array}$ \\
\hline & $\begin{array}{l}\text { - Associations between items and space are created in } \\
\text { WM, no LTM structure is put forward. } \\
\text { Items are associated via temporary bindings which } \\
\text { also link the items with locations in mental space } \\
\text { creating the spatial values }\end{array}$ & $\begin{array}{l}\text { Associations between items and space } \\
\text { are created in WM but the spatial } \\
\text { values come from an LTM structure } \\
\text { Items are given their spatial value in } \\
\text { WM when they interact with an LTM } \\
\text { template which is spatial in nature }\end{array}$ & $\begin{array}{l}\text { Associations between items and space are } \\
\text { created in WM but the spatial values come } \\
\text { from an LTM structure } \\
\text { Items are given their spatial value in WM } \\
\text { when they interact with an LTM } \\
\text { slotted-schema which is spatial and } \\
\text { expertise-depended }\end{array}$ \\
\hline
\end{tabular}

${ }^{1}$ Abrahamse et al. (2016) limited what comes from LTM in terms order to the canonical number set $1-9 .{ }^{2}$ We indicate that items belong to semantic memory, because recent results from Ginsburg et al. (2017) tend to suggest that for the SPoARC effect to occur, items need to be processed at a semantic level

also some differences between their paradigms and that in van Dijck and Fias's (2011) study. Ginsburg and Gevers intermingled classic trials (as just explained) with inducer trials in which the classification task (i.e., a number comparison tasks) had to be executed for all numbers, not only for those among the memoranda. And Huber et al. varied the number of elements in the memoranda (four, five, or six) and the range of the numbers (1-9 or 1-10) in the classification task (i.e., an odd-even judgment task); moreover, they used more trials (almost 2,000) than in van Dijck and Fias's study (400 trials).

Ginsburg and Gevers (2015) and Huber et al. (2016) interpreted their result (SNARC and SPoARC, but no interaction) as showing that the random sequences in WM (which produced the SPoARC) and the canonical 1-10 order (which produced the SNARC) were conjointly activated during the experiment but did not influence each other. They interpreted this result within the dual-account framework, as showing that both effects were produced by two distinct memory systems. The idea of a coexistence of both effects is more problematic for van Dijck and Fias's (2011) WM account, as one would expect only one set of elements to be activated in WM, the random sequence (which produces the SPoARC) or the canonical 1-10 order (which produces the SNARC). However, to accommodate the results, Abrahamse et al. (2016, p. 4) extended the WM account by adding a supplementary assumption: "multiple item sets can be active in working memory simultaneously." This would explain the results of Ginsburg and Gevers and Huber et al., in that both the random sequence and the canonical 1-10 order were in WM.

SNARC and SPoARC as mutually exclusive effects From the expertise-account perspective, we suggest that at one moment in time both effects are mutually exclusive, since we believe that the SPoARC effect is due to the spatial values generated by a specific slotted schema, and the SNARC effect by the spatial values generated by another structure, a nonslotted schema. Hence, we put forward the testable assumption that only one set of spatial values (or spatial frame) will be activated at any moment. At the item level, it means that at one moment in time an activated item is only associated with one spatial value, which comes from a slotted schema or a nonslotted schema. We can switch very quickly from a spatial frame to another, but only one is in the focus of attention at one precise moment. We put forward this assumption for two reasons. 
The first is due to the laws of physics of the world we live in, which mandate that an element cannot be at two places at the same moment. On the basis of grounded cognition (e.g., Barsalou, 2010; Glenberg, 1997; Shapiro, 2011), we believe that this physical principle observable by our perceptive system is internalized. This principle thus prevents an activated item from having two different spatial values (e.g., left and right) at any one moment.

Second, we believe that the lack of an interaction in Ginsburg and Gevers's (2015) and Huber et al.'s (2016) results can indicate that the SNARC and SPoARC effects are mutually exclusive. So why did the authors conclude the converse: both effects coexisted, and therefore were not mutually exclusive? This was because both effects can indeed coexist in the same experiment but be mutually exclusive at a trial level, ${ }^{9}$ so that during some trials, participants would activate the random sequence (which generates the SPoARC), and during other trials they would activate the canonical 1-10 order (which generates the SNARC). This could explain why no interaction was detected. This interpretation could be tested by looking at the reaction time distribution for trials in which the SPoARC and SNARC effects pulled in different directions. For example, if the memoranda were "9 5716 " and the 9 had to be classified, it should be linked to the left according to the SPoARC effect and to the right according to SNARC. Since there is no interaction between the two effects, we suggest that in some trials, 9 would be processed as belonging to the sequence and be linked to the left, but in other trials 9 would be processed as belonging to the canonical 1-10 order, and therefore linked to the right. Therefore, a bimodal distribution should appear for these kind of trials.

\section{Conclusion and future perspectives}

The purpose of this article was to show that an alternative to the dual account and the WM account, based on nonslotted (e.g., chunks) and slotted (e.g., templates) schemas was possible to account for the SNARC and SPoARC effects. In this concluding section, we would like to widen the lens by presenting the broader implications of our framework when considering knowledge structures, especially for WM.

We believe that one important purpose of these spatial knowledge structures is to enable individuals to organize and stabilize their thoughts in verbal WM. And we believe that people do so mainly in a horizontal, left-to-right fashion because of their writing/reading expertise. Usually the capacity to stabilize thoughts in face of interference in WM is linked to attentional control (or cognitive control, executive control, central executive, controlled attention, executive functioning, depending on the theory; see Chow \& Conway, 2015; Engle, 2002; Kane, Bleckley, Conway, \& Engle, 2001; Kane \& Engle, 2003). Here we do not want to replace this explanation (for a discussion see Guida, van Dijck, \& Abrahamse, 2017) but just stress the fact that knowledge structures, and especially slotted schemas, are important too, because they allow to reduce our need for attentional control. Indeed, we propose, as in Norman and Shallice's (1986) supervisory attentional system, that learned spatial schemas (or schemata, in Norman and Shallice's theory) enable people to be less dependent on attentional resources. Recent results by Mäntylä and colleagues (e.g., Mäntylä, 2013; Mäntylä, Coni, Kubik, Todorov, \& Del Missier, 2017; Todorov, Del Missier, Konke, \& Mäntylä, 2015; Todorov, Kubik, Carelli, Del Missier, \& Mäntylä, 2018) seem compatible with this idea. They showed that spatial abilities contribute to multitasking, and that when spatial coding was impeded, multitasking performance dropped. The results suggest that cognitive control demands can be offloaded by relying on spatial cognitive structures and processes.

Therefore, the involvement of attentional control could be an inverse function of expertise and knowledge. If reading/ writing has been practiced for a long period of years, it should have generated the capacity to use this horizontal, left-to-right schema with less attentional control than if less practiced. Or said otherwise, if an illiterate individual wants to achieve the same kind of spatialization as an experienced reader, he will have to use a lot of attentional control to stabilize the information in a horizontal, left-to-right fashion.

Obviously (and interestingly), the picture gets more complex if one considers that attentional control is certainly important to first acquiring the knowledge of schemas, and subsequently to increasing expertise. Several studies (e.g., Engle, Carullo, \& Collins, 1991; Gathercole \& Baddeley, 2014; Gathercole, Brown, \& Pickering, 2003) have shown a link between language acquisition and WM (used here as an approximation of attentional control). In other words, attention control could be important to acquire knowledge; however, once acquired, knowledge could enable less attentional control to be used, as occurs with chunking in experts (Guida et al., 2012). As a consequence, high/low WM span differences could partly be due to the capacity to use schemas through knowledge and expertise in a way similar to that proposed by Ericsson and Kintsch (1995). This can be exemplified by mind wandering. As was shown by Kane et al. (2007), individuals with low WM span seem to "suffer" more from mind-wandering than do high-WM-span individuals. This seems to be due to their lack of cognitive control. Our idea would be that part of the capacity of individuals with high WM span to control their thoughts may come from the capacity to use well-practiced schemas (knowledge), such as an horizontal, left-to-right spatial schema, to stabilize their thoughts more easily. Therefore, the disadvantage of individuals with low WM span may come from both their lack of attentional control and lack of cognitive stabilizing structures.

Finally, we conclude this section by stating three principles that derive from our account. The first is the knowledge principle, which states that an average adult individual always 
uses knowledge to process and remember information; in fact, we cannot not use knowledge. This principle highlights an idea shared with many WM models (e.g., Acheson \& MacDonald, 2009a, 2009b; Burgess \& Hitch, 1999; Majerus, 2008; Martin \& Saffran, 1992) that WM theories should not be built around the idea that we have empty stores that can be filled, but instead on the idea that the capacity to store information is a consequence of knowledge structures we build and use to store. Second is the expertise principle, which states that in the domains in which we have more expertise, we are able to use more appropriate knowledge structures, and therefore to increase our capacity to remember information. Third and last is the development principle: We develop knowledge structures based on our experience with the world, and we use these structures to remember. The SNARC and the SPoARC effects are two examples of how we have developed apt cognitive structures.

Author note G.C. was granted a Visiting Fellow (Research) Grant by the School of Arts and Humanities at Edith Cowan University in order to invite A.G.. A.G. thanks the section 16 of the Conseil National des Universités for awarding him a 6 month sabbatical (C.R.C.T.). The authors declare that the research was conducted in the absence of any commercial or financial relationships that could be construed as a potential conflicts of interest.

\section{References}

Abrahamse, E., van Dijck, J.-P., \& Fias, W. (2016). How does working memory enable number-induced spatial biases? Frontiers in Psychology, 7, 977. https://doi.org/10.3389/fpsyg.2016.00977

Abrahamse, E., van Dijck, J.-P., Majerus, S., \& Fias, W. (2014). Finding the answer in space: The mental whiteboard hypothesis on serial order in working memory. Frontiers in Human Neuroscience, 8, 932. https://doi.org/10.3389/fnhum.2014.00932

Abrahamse, E. L., van Dijck, J.-P., \& Fias, W. (2017). Grounding verbal working memory: The case of serial order. Current Directions in Psychological Science, 26, 429-433.

Acheson, D. J., \& MacDonald, M. C. (2009a). Twisting tongues and memories: Explorations of the relationship between language production and verbal working memory. Journal of Memory and Language, 60, 329-350. https://doi.org/10.1016/j.jml.2008.12.002

Acheson, D. J., \& MacDonald, M. C. (2009b). Verbal working memory and language production: Common approaches to the serial ordering of verbal information. Psychological Bulletin, 135, 50-68. https:// doi.org/10.1037/a0014411

Anderson, J. R., \& Matessa, M. (1997). A production system theory of serial memory. Psychological Review, 104, 728-748. https://doi.org/ 10.1037/0033-295X.104.4.728

Anderson, J. R., Reder, L. M., \& Lebiere, C. (1996). Working memory: Activation limitations on retrieval. Cognitive Psychology, 30, 221256.

Antoine, S., Ranzini, M., Gebuis, T., van Dijck, J.-P., \& Gevers, W. (2017). Order information in verbal working memory shifts the subjective midpoint in both the line bisection and the landmark tasks. Quarterly Journal of Experimental Psychology, 70, 1973-1983.
Baddeley, A. (1986). Working memory. New York: Oxford University Press, Clarendon Press.

Baddeley, A. (2000). The episodic buffer: A new component of working memory? Trends in Cognitive Sciences, 4, 417-423. https://doi.org/ 10.1016/S1364-6613(00)01538-2

Baddeley, A. D., \& Hitch, G. J. (1974). Working memory. In G. H. Bower (Ed.), The psychology of learning and motivation: Advances in research and theory (Vol. 8, pp. 47-89). New York: Academic Press. https://doi.org/10.1016/S0079-7421(08)60452-1

Barrouillet, P., Bernardin, S., \& Camos, V. (2004). Time constraints and resource sharing in adults' working memory spans. Journal of Experimental Psychology: General, 133, 83-100. https://doi.org/ 10.1037/0096-3445.133.1.83

Barsalou, L. W. (2010). Grounded cognition: Past, present, and future. Topics in Cognitive Science, 2, 716-724.

Becker, S. L. (1953). The ordinal position effect. Quarterly Journal of Speech, 39, 217-219.

Bjork, E. L., \& Healy, A. F. (1974). Short-term order and item retention. Journal of Verbal Learning and Verbal Behavior, 13, 80-97.

Boiteau, T. W., \& Almor, A. (2017). Transitivity, space, and hand: The spatial grounding of syntax. Cognitive Science, 41, 848-891. https:// doi.org/10.1111/cogs. 12355

Bottini, R., Mattioni, S., \& Collignon, O. (2016). Early blindness alters the spatial organization of verbal working memory. Cortex, 83, 271279.

Brown, G. D. A., Neath, I., \& Chater, N. (2007). A temporal ratio model of memory. Psychological Review, 114, 539-576. https://doi.org/10. 1037/0033-295X.114.3.539

Brown, G. D. A., Preece, T., \& Hulme, C. (2000). Oscillator-based memory for serial order. Psychological Review, 107, 127-181. https://doi. org/10.1037/0033-295X.107.1.127

Brysbaert, M. (1995). Arabic number reading: On the nature of the numerical scale and the origin of phonological recoding. Journal of Experimental Psychology: General, 124, 434-452. https://doi.org/ 10.1037/0096-3445.124.4.434

Burgess, N., \& Hitch, G. J. (1999). Memory for serial order: A network model of the phonological loop and its timing. Psychological Review, 106, 551-581. https://doi.org/10.1037/0033-295X.106.3. 551

Campitelli, G. (2015). Memory behavior requires knowledge structures, not memory stores. Frontiers in Psychology, 6, 1696. https://doi.org/ 10.3389/fpsyg.2015.01696

Chase, W. G., \& Ericsson, K. A. (1981). Skilled memory. In J. R. Anderson (Ed.), Cognitive skills and their acquisition (pp. 141189). Hillsdale: Erlbaum.

Chase, W. G., \& Ericsson, K. A. (1982). Skill and working memory. In G. H. Bower (Ed.), The psychology of learning and motivation: Advances in research and theory (Vol. 16, pp. 1-58). New York: Academic Press. https://doi.org/10.1016/S0079-7421(08)60546-0

Chase, W. G., \& Simon, H. A. (1973). Perception in chess. Cognitive Psychology, 4, 55-81.

Chow, M., \& Conway, A. R. (2015). The scope and control of attention: Sources of variance in working memory capacity. Memory \& Cognition, 43, 325-339.

Cipora, K., Hohol, M., Nuerk, H.-C., Willmes, K., Brożek, B., Kucharzyk, B., \& Nęcka, E. (2016). Professional mathematicians differ from controls in their spatial-numerical associations. Psychological Research, 80, 710-726. https://doi.org/10.1007/ s00426-015-0677-6

Cowan, N. (1995). Attention and memory: An integrated framework. New York: Oxford University Press.

Cowan, N. (2001). The magical number 4 in short-term memory: A reconsideration of mental storage capacity. Behavioral and Brain Sciences, 24, 87-114, disc. 114-185. https://doi.org/10.1017/ S0140525X01003922 
Cowan, N. (2012). Working memory capacity. New York: Psychology Press.

Dale, R. H. (1987). Similarities between human and animal spatial memory: Item and order information. Animal Learning \& Behavior, 15, 293-300.

Darling, S., Allen, R. J., \& Havelka, J. (2017). Visuospatial bootstrapping: When visuospatial and verbal memory work together. Current Directions in Psychological Science, 26, 3-9.

Darling, S., Allen, R. J., Havelka, J., Campbell, A., \& Rattray, E. (2012). Visuospatial bootstrapping: Long-term memory representations are necessary for implicit binding of verbal and visuospatial working memory. Psychonomic Bulletin \& Review, 19, 258-263. https://doi. org/10.3758/s13423-011-0197-3

Darling, S., \& Havelka, J. (2010). Visuospatial bootstrapping: Evidence for binding of verbal and spatial information in working memory. Quarterly Journal of Experimental Psychology, 63, 239-245.

De Belder, M., Abrahamse, E., Kerckhof, E., Fias, W., \& van Dijck, J. P. (2015). Serial position markers in space: Visuospatial priming of serial order working memory retrieval. PLoS ONE, 10, e0116469. https://doi.org/10.1371/journal.pone.0116469

de Groot, A. D. C. (1965). Thought and choice in chess. The Hague: Mouton.

Dehaene, S., Bossini, S., \& Giraux, P. (1993). The mental representation of parity and number magnitude. Journal of Experimental Psychology: General, 122, 371-396. https://doi.org/10.1037/00963445.122.3.371

Dehaene, S., Dupoux, E., \& Mehler, J. (1990). Is numerical comparison digital? Analogical and symbolic effects in two-digit number comparison. Journal of Experimental Psychology: Human Perception and Performance, 16, 626-641. https://doi.org/10.1037/00961523.16.3.626

Demoulin, C., \& Kolinsky, R. (2016). Does learning to read shape verbal working memory?. Psychonomic Bulletin \& Review, 23, 703-722.

Engelkamp, J., \& Dehn, D. M. (2000). Item and order information in subject-performed tasks and experimenter-performed tasks. Journal of Experimental Psychology: Learning, Memory, and Cognition, 26, 671-682. https://doi.org/10.1037/0278-7393.26.3. 671

Engle, R. W. (2002). Working memory capacity as executive attention. Current Directions in Psychological Science, 11, 19-23. https://doi. org/10.1111/1467-8721.00160

Engle, R. W., Carullo, J. J., \& Collins, K. W. (1991). Individual differences in working memory for comprehension and following directions. Journal of Educational Research, 84, 253-262. https://doi. org/10.1080/00220671.1991.10886025

Ericsson, K. A. (1985). Memory skill. Canadian Journal of Psychology, 39, 188-231.

Ericsson, K. A., Chase, W. G., \& Faloon, S. (1980). Acquisition of a memory skill. Science, 208, 1181-1182.

Ericsson, K. A., \& Delaney, P. F. (1999). Long-term working memory as an alternative to capacity models of working memory in everyday skilled performance. In A. Miyake \& P. Shah (Eds.), Models of working memory: Mechanisms of active maintenance and executive control (pp. 257-297). New York: Cambridge University Press.

Ericsson, K. A., \& Kintsch, W. (1995). Long-term working memory. Psychological Review, 102, 211-245. https://doi.org/10.1037/ 0033-295X.102.2.211

Ericsson, K. A., \& Kintsch, W. (2000). Shortcomings of generic retrieval structures with slots of the type that Gobet (1993) proposed and modelled. British Journal of Psychology, 91(Pt. 4), 571-590, disc. 591-594.

Fias, W. (2001). Two routes for the processing of verbal numbers: Evidence from the SNARC effect. Psychological Research, 65, 250-259. https://doi.org/10.1007/s004260100065
Fias, W., \& Fischer, M. H. (2005). Spatial representation of numbers. In J. I. D. Campbell (Ed.), Handbook of mathematical cognition (pp. 43 54). New York: Psychology Press.

Fias, W., van Dijck, J.-P., \& Gevers, W. (2011). How is number associated with space? The role of working memory. In S. Dehaene \& E. Brannon (Eds.), Space, time and number in the brain: Searching for the foundations of mathematical thought (pp. 133-148). San Diego: Elsevier Academic Press.

Gathercole, S. E., \& Baddeley, A. D. (2014). Working memory and language (2nd). New York: Psychology Press.

Gathercole, S. E., Brown, L., \& Pickering, S. J. (2003). Working memory assessments at school entry as longitudinal predictors of National Curriculum attainment levels. Educational and Child Psychology, 20, 109-122.

Gevers, W., \& Lammertyn, J. (2005). The hunt for SNARC. Psychology Science, 47, 10-21.

Gevers, W., Reynvoet, B., \& Fias, W. (2003). The mental representation of ordinal sequences is spatially organized. Cognition, 87, B87B95. https://doi.org/10.1016/S0010-0277(02)00234-2

Gevers, W., Reynvoet, B., \& Fias, W. (2004). The mental representation of ordinal sequences is spatially organised: Evidence from days of the week. Cortex, 40, 171-172.

Ginsburg, V., Archambeau, K., van Dijck, J.-P., Chetail, F., \& Gevers, W. (2017). Coding of serial order in verbal, visual and spatial working memory. Journal of Experimental Psychology: General, 146, 632650. https://doi.org/10.1037/xge0000278

Ginsburg, V., \& Gevers, W. (2015). Spatial coding of ordinal information in short-and long-term memory. Frontiers in Human Neuroscience, 9, 8. https://doi.org/10.3389/fnhum.2015.00008

Ginsburg, V., van Dijck, J.-P., Previtali, P., Fias, W., \& Gevers, W. (2014). The impact of verbal working memory on number-space associations. Journal of Experimental Psychology: Learning, Memory, and Cognition, 40, 976-986. https://doi.org/10.1037/a0036378

Glenberg, A. M. (1997). What memory is for. Behavioral and Brain Sciences, 20, 1-19.

Gobet, F. (2000). Some shortcomings of long-term working memory. British Journal of Psychology, 91, 551-570.

Gobet, F. (2013). Chunks and templates in semantic long-term memory: The importance of specialization. In J. J. Staszewski (Ed.), Expertise and skills acquisition: The impact of William G. Chase (pp. 117146). New York: Psychology Press.

Gobet, F., Lane, P. C. R., Croker, S., Cheng, P. C.-H., Jones, G., Oliver, I., \& Pine, J. M. (2001). Chunking mechanisms in human learning. Trends in Cognitive Sciences, 5, 236-243. https://doi.org/10.1016/ S1364-6613(00)01662-4

Gobet, F., Lane, P. C. R., \& Lloyd-Kelly, M. (2015). Chunks, schemata, and retrieval structures: Past and current computational models. Frontiers in Psychology, 6, 1785. https://doi.org/10.3389/fpsyg. 2015.01785

Gobet, F., \& Simon, H. A. (1996). Templates in chess memory: A mechanism for recalling several boards. Cognitive Psychology, 31, 1-40.

Guida, A., Campitelli, G., \& Gobet, F. (2016). Becoming an expert: Ontogeny of expertise as an example of neural reuse. Behavioral and Brain Sciences, 39, e123. https://doi.org/10.1017/ S0140525X15001570

Guida, A., Carnet, S., Normandon, M., \& Lavielle-Guida, M. (2018). Can spatialisation be extended to episodic memory and open sets? Memory, 26, 922-935. https://doi.org/10.1080/09658211.2018. 1428350

Guida, A., Gobet, F., \& Nicolas, S. (2013). Functional cerebral reorganization: A signature of expertise? Reexamining Guida, Gobet, Tardieu, and Nicolas' (2012) two-stage framework. Frontiers in Human Neuroscience, 7, 590. https://doi.org/10.3389/fnhum.2013. 00590

Guida, A., Gobet, F., Tardieu, H., \& Nicolas, S. (2012). How chunks, long-term working memory and templates offer a cognitive 
explanation for neuroimaging data on expertise acquisition: a twostage framework. Brain and Cognition, 79, 221-244.

Guida, A., \& Lavielle-Guida, M. (2014). 2011 space odyssey: Spatialization as a mechanism to code order allows a close encounter between memory expertise and classic immediate memory studies. In G. Campitelli, M. H. Connors, M. Bilalić, \& D. Z. Hambrick (Eds.), Psychological perspectives on expertise (pp. 176-180). New York: Frontiers Media SA.

Guida, A., Leroux, A., Lavielle-Guida, M., \& Noël, Y. (2016). A SPoARC in the dark: Spatialization in verbal immediate memory. Cognitive Science, 40, 2108-2121.

Guida, A., Megreya, A. M., Lavielle-Guida, M., Noël, Y., Mathy, F., van Dijck, J.-P., \& Abrahamse, E. (2018). Spatialization in working memory is related to literacy and reading direction: Culture "literarily" directs our thoughts. Cognition, 175, 96-100. https:// doi.org/10.1016/j.cognition.2018.02.013

Guida, A., van Dijck, J. P., \& Abrahamse, E. (2017). Distinctiveness as a function of spatial expansion in verbal working memory: comment on Kreitz, Furley, Memmert, and Simons (2015). Psychological Research, 81(3), 690-695.

Gupta, P. (2003). Examining the relationship between word learning, nonword repetition, and immediate serial recall in adults. Quarterly Journal of Experimental Psychology, 56A, 1213-1236. https://doi.org/10.1080/02724980343000071

Henson, R., Hartley, T., Burgess, N., Hitch, G., \& Flude, B. (2003). Selective interference with verbal short-term memory for serial order information: A new paradigm and tests of a timing-signal hypothesis. Quarterly Journal of Experimental Psychology, 56A, 13071334.

Herrera, A., Macizo, P., \& Semenza, C. (2008). The role of working memory in the association between number magnitude and space. Acta Psychologica, 128, 225-237. https://doi.org/10.1016/j.actpsy. 2008.01.002

Huber, S., Klein, E., Moeller, K., \& Willmes, K. (2016). Spatialnumerical and ordinal positional associations coexist in parallel. Frontiers in Psychology, 7, 438. https://doi.org/10.3389/fpsyg. 2016.00438

Hulme, C., Maughan, S., \& Brown, G. D. A. (1991). Memory for familiar and unfamiliar words: Evidence for a long-term memory contribution to short-term memory span. Journal of Memory and Language, 30, 685-701.

Hung, Y., Hung, D. L., Tzeng, O. J.-L., \& Wu, D. H. (2008). Flexible spatial mapping of different notations of numbers in Chinese readers. Cognition, 106, 1441-1450.

Hurlstone, M. J., Hitch, G. J., \& Baddeley, A. D. (2014). Memory for serial order across domains: An overview of the literature and directions for future research. Psychological Bulletin, 140, 339-373. https://doi.org/10.1037/a0034221

Ito, Y., \& Hatta, T. (2004). Spatial structure of quantitative representation of numbers: Evidence from the SNARC effect. Memory \& Cognition, 32, 662-673. https://doi.org/10.3758/BF03195857

Just, M. A., \& Carpenter, P. A. (1992). A capacity theory of comprehension: Individual differences in working memory. Psychological Review, 99, 122-149. https://doi.org/10.1037/0033-295X.99.1.122

Kane, M. J., Bleckley, M. K., Conway, A. R. A., \& Engle, R. W. (2001). A controlled-attention view of working-memory capacity. Journal of Experimental Psychology: General, 130, 169-183. https://doi. org/10.1037/0096-3445.130.2.169

Kane, M. J., Brown, L. H., McVay, J. C., Silvia, P. J., Myin-Germeys, I., \& Kwapil, T. R. (2007). For whom the mind wanders, and when: An experience-sampling study of working memory and executive control in daily life. Psychological Science, 18, 614-621.

Kane, M. J., \& Engle, R. W. (2003). Working-memory capacity and the control of attention: The contributions of goal neglect, response competition, and task set to Stroop interference. Journal of
Experimental Psychology: General, 132, 47-70. https://doi.org/10. 1037/0096-3445.132.1.47

Kosmidis, M. H., Zafiri, M., \& Politimou, N. (2011). Literacy versus formal schooling: Influence on working memory. Archives of Clinical Neuropsychology, 26, 575-582.

Kowialiewski, B., \& Majerus, S. (2018). The non-strategic nature of linguistic long-term memory effects in verbal short-term memory. Journal of Memory and Language, 101, 64-83.

Kramer, P., Bressan, P., \& Grassi, M. (2018). The SNARC effect is associated with worse mathematical intelligence and poorer time estimation. Royal Society Open Science, 5, 172362.

Luck, S. J., \& Vogel, E. K. (1997). The capacity of visual working memory for features and conjunctions. Nature, 390, 279-281. https://doi. org $/ 10.1038 / 36846$

Majerus, S. (2008). Verbal short-term memory and temporary activation of language representations: The importance of distinguishing item and order information. In A. Thorn \& M. Page (Eds.), Interactions between short-term and long-term memory in the verbal domain (pp. 244-276). Hove: Psychology Press.

Majerus, S., \& Attout, L. (2018). Working memory for serial order and numerical cognition: What kind of association? In A. Henik \& W. Fias (Eds.), Heterogeneity of function in numerical cognition (pp. 409-431). San Diego: Academic Press.

Majerus, S., Heiligenstein, L., Gautherot, N., Poncelet, M., \& Van der Linden, M. (2009). The impact of auditory selective attention on verbal short-term memory and vocabulary development. Journal of Experimental Child Psychology, 103, 66-86.

Majerus, S., Poncelet, M., Elsen, B., \& van der Linden, M. (2006). Exploring the relationship between new word learning and shortterm memory for serial order recall, item recall, and item recognition. European Journal of Cognitive Psychology, 18, 848-873.

Mäntylä, T. (2013). Gender differences in multitasking reflect spatial ability. Psychological Science, 24, 514-520. https://doi.org/10. 1177/0956797612459660

Mäntylä, T., Coni, V., Kubik, V., Todorov, I., \& Del Missier, F. (2017). Time takes space: Selective effects of multitasking on concurrent spatial processing. Cognitive Processing, 18, 229-235.

Marshuetz, C. (2005). Order information in working memory: An integrative review of evidence from brain and behavior. Psychological Bulletin, 131, 323-339. https://doi.org/10.1037/0033-2909.131.3.323

Martarelli, C. S., Mast, F. W., \& Hartmann, M. (2017). Time in the eye of the beholder: Gaze position reveals spatial-temporal associations during encoding and memory retrieval of future and past. Memory \& Cognition, 45, 40-48.

Martin, N., \& Saffran, E. M. (1992). A computational account of deep dysphasia: Evidence from a single case study. Brain and Language, 43, 240-274.

Mathy, F., \& Feldman, J. (2012). What's magic about magic numbers? Chunking and data compression in short-term memory. Cognition, $122,346-362$.

McCrink, K., Caldera, C., \& Shaki, S. (2018). The early construction of spatial attention: Culture, space, and gesture in parent-child interactions. Child Development, 89, 1141-1156.

McCrink, K., \& Opfer, J. E. (2014). Development of spatial-numerical associations. Current Directions in Psychological Science, 23, 439-445.

McCrink, K., Shaki, S., \& Berkowitz, T. (2014). Culturally driven biases in preschoolers' spatial search strategies for ordinal and non-ordinal dimensions. Cognitive Development, 30, 1-14.

Mulligan, N. W. (1999). The effects of perceptual interference at encoding on organization and order: Investigating the roles of item-specific and relational information. Journal of Experimental Psychology: Learning, Memory, and Cognition, 25, 54-69. https:// doi.org/10.1037/0278-7393.25.1.54

Norman, D. A., \& Shallice, T. (1986). Attention to action: Willed and automatic control of behavior. In R. J. Davidson, G. E. Schwartz, \& 
D. Shapiro (Eds.), Consciousness and self-regulation: Advances in research (Vol. 4, pp. 1-18). New York: Plenum Press.

Oberauer, K. (2002). Access to information in working memory: Exploring the focus of attention. Journal of Experimental Psychology: Learning, Memory, and Cognition, 28, 411-421. https://doi.org/10.1037/0278-7393.28.3.411

Oberauer, K., \& Lewandowsky, S. (2011). Modeling working memory: A computational implementation of the Time-Based Resource-Sharing theory. Psychonomic Bulletin \& Review, 18, 10-45. https://doi.org/ 10.3758/s13423-010-0020-6

Opfer, J. E., Thompson, C. A., \& Furlong, E. E. (2010). Early development of spatial-numeric associations: Evidence from spatial and quantitative performance of preschoolers: Spatial-numeric associations. Developmental Science, 13, 761-771.

Patro, K., Nuerk, H.-C., Cress, U., \& Haman, M. (2014). How numberspace relationships are assessed before formal schooling: A taxonomy proposal. Frontiers in Psychology, 5, 419. https://doi.org/10. 3389/fpsyg.2014.00419

Portrat, S., Guida, A., Phénix, T., \& Lemaire, B. (2016). Promoting the experimental dialogue between working memory and chunking: Behavioral data and simulation. Memory \& Cognition, 44, 420 434. https://doi.org/10.3758/s13421-015-0572-9

Previtali, P., Hevia, M. D., \& Girelli, L. (2009). Placing order in space: The SNARC effect in serial learning. Experimental Brain Research, 201, 599-605.

Richman, H. B., Staszewski, J. J., \& Simon, H. A. (1995). Simulation of expert memory using EPAM IV. Psychological Review, 102, 305330. https://doi.org/10.1037/0033-295X.102.2.305

Rinaldi, L., Brugger, P., Bockisch, C. J., Bertolini, G., \& Girelli, L. (2015). Keeping an eye on serial order: Ocular movements bind space and time. Cognition, 142, 291-298.

Rinaldi, L., Merabet, L. B., Vecchi, T., \& Cattaneo, Z. (2018). The spatial representation of number, time, and serial order following sensory deprivation: A systematic review. Neuroscience \& Biobehavioral Reviews, 90, 371-380.

Roodenrys, S., Hulme, C., Alban, J., Ellis, A. W., \& Brown, G. D. A. (1994). Effects of word frequency and age of acquisition on shortterm memory span. Memory \& Cognition, 22, 695-701. https://doi. org/10.3758/BF03209254

Schweickert, R. (1993). A multinomial processing tree model for degradation and redintegration in immediate recall. Memory \& Cognition, 21, 168-175. https://doi.org/10.3758/BF03202729

Sellaro, R., Treccani, B., Job, R., \& Cubelli, R. (2015). Spatial coding of object typical size: evidence for a SNARC-like effect. Psychological Research, 79, 950-962.

Shaki, S., Fischer, M. H., \& Göbel, S. M. (2012). Direction counts: A comparative study of spatially directional counting biases in cultures with different reading directions. Journal of Experimental Child Psychology, 112, 275-281.

Shaki, S., Fischer, M. H., \& Petrusic, W. M. (2009). Reading habits for both words and numbers contribute to the SNARC effect. Psychonomic Bulletin \& Review, 16, 328-331. https://doi.org/10. 3758/PBR.16.2.328

Shapiro, L. (2011). Embodied cognition. New York: Routledge.

Silva, C., Faísca, L., Ingvar, M., Petersson, K. M., \& Reis, A. (2012). Literacy: Exploring working memory systems. Journal of Clinical and Experimental Neuropsychology, 34, 369-377.

Simon, J. R., \& Rudell, A. P. (1967). Auditory S-R compatibility: The effect of an irrelevant cue on information processing. Journal of Applied Psychology, 51, 300-304. https://doi.org/10.1037/h0020586

Sperling, G., \& Melchner, M. J. (1976). Estimating item and order information. Journal of Mathematical Psychology, 13, 192-213.
Todorov, I., Del Missier, F., Konke, L. A., \& Mäntylä, T. (2015). Deadlines in space: Selective effects of coordinate spatial processing in multitasking. Memory \& Cognition, 43, 1216-1228.

Todorov, I., Kubik, V., Carelli, M. G., Del Missier, F., \& Mäntylä, T. (2018). Spatial offloading in multiple task monitoring. Journal of Cognitive Psychology, 30, 230-241. https://doi.org/10.1080/ 20445911.2018.1436551

Towse, J. N., Cowan, N., Hitch, G. J., \& Horton, N. J. (2008). The recall of information from working memory: Insights from behavioural and chronometric perspectives. Experimental Psychology, 55, 371-383.

Umiltà, C., Bonato, M., \& Rusconi, E. (2018). S-R compatibility with physical and representational locations. In T. L. Hubbard (Ed.), Spatial biases in perception and cognition (pp. 60-76). Cambridge: Cambridge University Press.

van Dijck, J.-P., Abrahamse, E. L., Acar, F., Ketels, B., \& Fias, W. (2014). A working memory account of the interaction between numbers and spatial attention. Quarterly Journal of Experimental Psychology, 67, 1500-1513. https://doi.org/10.1080/17470218.2014.903984

van Dijck, J.-P., Abrahamse, E. L., Majerus, S., \& Fias, W. (2013). Spatial attention interacts with serial-order retrieval from verbal working memory. Psychological Science, 24, 1854-1859.

van Dijck, J.-P., \& Fias, W. (2011). A working memory account for spatial-numerical associations. Cognition, 119, 114-119.

van Dijck, J.-P., Fias, W., \& Andres, M. (2015). Selective interference of grasp and space representations with number magnitude and serial order processing. Psychonomic Bulletin \& Review, 22, 1370-1376. https://doi.org/10.3758/s13423-014-0788-x

van Dijck, J.-P., Gevers, W., \& Fias, W. (2009). Numbers are associated with different types of spatial information depending on the task. Cognition, 113, 248-253. https://doi.org/10.1016/j.cognition.2009. 08.005

van Dijk, T. A., \& Kintsch, W. (1983). Strategies of discourse comprehension. New York: Academic Press.

Walker, I., \& Hulme, C. (1999). Concrete words are easier to recall than abstract words: Evidence for a semantic contribution to short-term serial recall. Journal of Experimental Psychology: Learning, Memory, and Cognition, 25, 1256-1271. https://doi.org/10.1037/ 0278-7393.25.5.1256

Williamon, A., \& Valentine, E. (2002). The role of retrieval structures in memorizing music. Cognitive Psychology, 44, 1-32.

Wood, G., Nuerk, H.-C., \& Willmes, K. (2006). Crossed hands and the SNARC effect: A failure to replicate Dehaene, Bossini, and Giraux (1993). Cortex, 42, 1069-1079. https://doi.org/10.1016/S00109452(08)70219-3

Wood, G., Willmes, K., Nuerk, H.-C., \& Fischer, M. H. (2008). On the cognitive link between space and number: A meta-analysis of the SNARC effect. Psychology Science Quarterly, 50, 489-525.

Worthen, J. B., \& Hunt, R. R. (2011). Mnemonology: Mnemonics for the 21st century. New York: Psychology Press.

Yates, F. A. (1966). The art of memory. Chicago: University of Chicago Press.

Zebian, S. (2005). Linkages between number concepts, spatial thinking, and directionality of writing: The SNARC effect and the reverse SNARC effect in English and Arabic monoliterates, biliterates, and illiterate Arabic speakers. Journal of Cognition and Culture, 5, 165-190. https://doi.org/10.1163/1568537054068660

Publisher's note Springer Nature remains neutral with regard to jurisdictional claims in published maps and institutional affiliations. 